\title{
SV40 T-Antigen Amino Acid Changes that Disrupt Cul-7 or Bub-1 Binding Do Not Globally Distort the T-Common Region
}

\author{
Jane F. Cavender ${ }^{a}$ Mary J. Tevethia ${ }^{a, b}$ \\ a Department of Biology, Elizabethtown College, Elizabethtown, Pa., and ${ }^{\mathrm{b}}$ Department of Microbiology and \\ Immunology, Pennsylvania State University College of Medicine, Hershey, Pa., USA
}

\section{Key Words}

Polyomavirus - SV40 T antigen - Monoclonal antibody .

Epitope $\cdot$ Cul-7 $\cdot$ Bub-1

\begin{abstract}
Background: Amino acids 1-107 of the SV40 T antigen constitute a functionally important and complex region. Cellular proteins, Hsc70, Bub-1, Cul-7, and Rb, each of which is involved in cell growth control or genomic stability, bind within this portion of the $\mathrm{T}$ antigen. Mutational analysis has mapped the J domain/Hsc70, Bub-1, and the Rb binding motifs. Two regions of the $T$ antigen have been implicated in Cul-7 binding. Mutation of F98A diminished Cul-7 binding, and deletion of amino acids 68-83 abolished it. The authors suggest, based on T-antigen structure, that F98 is inaccessible and that the F98A change altered the configuration of the upstream region, preventing Cul-7 binding. Our objective was to determine, by using monoclonal $\mathrm{T}$-antigen antibodies, whether F98 is accessible and whether F98A substitution globally distorted the T-common region. Methods: Cell-expressing $\mathrm{T}$ antigens, immunoprecipitation, and immunoblot were used to determine the accessibility of amino acids. Conclusion: Full-length $\mathrm{T}$-antigen and $\mathrm{N}$-terminal fragments containing F98A were immunoprecipitated by
\end{abstract}

monoclonal antibody PAb902, which recognizes a conformation-dependent epitope within the first 82 amino acids. Therefore, this alteration does not globally distort the entire T-common region. Additionally, PAb416, which displaces Cul-7 from the $T$ antigen and immunoprecipitates bound pRb peptides, depends on F98 for binding, implying that amino acid 98 is part of the epitope and accessible in the native $T$ antigen.

(C) 2016 The Author(s)

Published by S. Karger AG, Basel

The small DNA tumor virus SV40 readily transforms cells in culture and induces tumors in experimental and transgenic animals. The transformed tumor cells express three virus-coded proteins, the large $\mathrm{T}, 17 \mathrm{KT}$ and small $\mathrm{t}$ antigens. These three proteins contain the same N-terminal 82 amino acids (the T-common region) followed in each case by a unique amino acid sequence [1]. Among these proteins the large $\mathrm{T}$ antigen is the major viral oncoprotein and is sufficient to convert normal rodent cells to tumor cells.

Monoclonal T-antigen antibodies have been instrumental in identifying proteins that bind to the $\mathrm{T}$ antigen, locating or confirming the binding sites for these proteins on the T antigen [2], identifying subsets of the T antigen

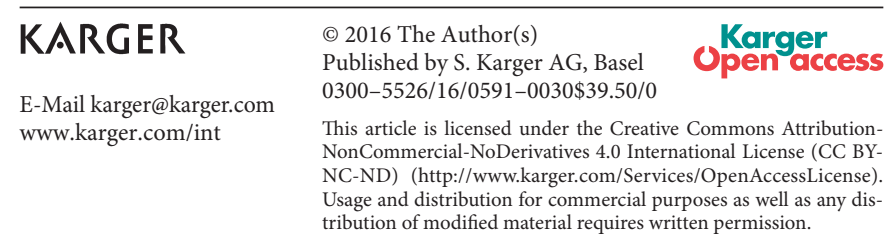

Jane F. Cavender

Department of Biology, Elizabethtown College

1 Alpha Drive

Elizabethtown, PA 17022 (USA)

E-Mail cavender@etown.edu 
Fig. 1. T antigen showing the binding sites for cellular proteins and monoclonal antibodies as well as positions of mutants used. aa = Amino acids. Amino acids 122-676 have been omitted for simplicity.

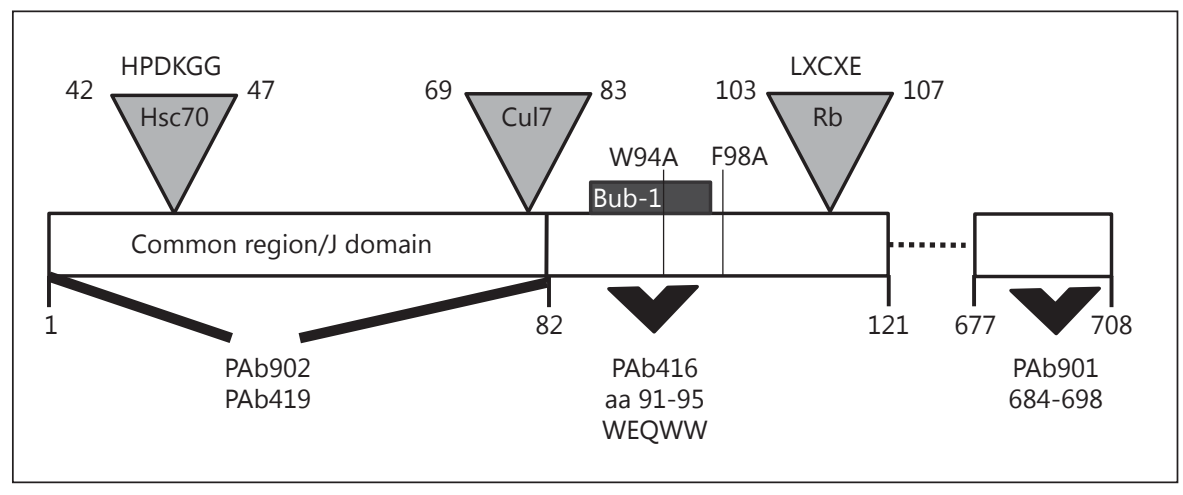

with unique conformations $[3,4]$, and disrupting specific $\mathrm{T}$-antigen functions in vitro [5].

We examined $\mathrm{T}$-antigen complexes with multiple cellular proteins (fig. 1). The $\mathrm{T}$ antigen binds and functionally sequesters two major tumor suppressor proteins, $\mathrm{Rb}$ and p53, each of which in its unbound, active form is central to maintaining normal cell proliferation and genomic integrity. Binding these tumor suppressor proteins is essential to the ability of the $\mathrm{T}$ antigen to convert normal cells to transformed or tumor cells in vitro [6] and in vivo [7]. Recently, the $\mathrm{T}$ antigen was shown to bind two additional cellular proteins, Cul-7 [8] and Bub1 [9], implicated in normal cell growth [10] and genomic stability [11], respectively. Rb, Cul-7, and Bub-1 bind within the first 107 amino acids of the T antigen $[12,13]$. Multiple monoclonal antibodies bind within this same T-antigen region (fig. 1). PAb902 [14], PAb419, and 430 [15] bind within the $\mathrm{N}$-terminal 82 amino acids shared among the three SV40 T antigens [16]. Thus, these antibodies will immunoprecipitate all three $\mathrm{T}$ antigens from cell lysates. PAb416 immunoprecipitates full-length $\mathrm{T}$ and $17 \mathrm{KT}$ antigens but not the small $t$ antigen, indicating that its epitope lies outside of the T-common region. PAb902 is conformation dependent and will detect native but not denatured $\mathrm{T}$ antigens [17]. PAb419 and PAb416 detect both native and denatured $\mathrm{T}$ antigens and, therefore, recognize conformation-independent (linear) epitopes.

The binding site for PAb416, first identified by immunoprecipitation of truncated and deletion mutant $\mathrm{T}$ antigens [15], was localized between T-antigen amino acids 83 and 118. Later, Lindner et al. [18] (1998) showed by using overlapping synthetic peptides in ELISA assays that 15 mer peptides containing the five amino acids WEQWW bound to the antibody. They, therefore, defined the minimal PAb416 epitope as T-antigen amino acids 91-95.

Cul-7 and Bub-1 Binding Mutants

Maintain Conformation of Epitope
The interaction of PAb416 and the T antigen impacts the ability to detect specific cellular proteins bound to the $\mathrm{T}$ antigen. Monoclonal antibodies directed to either the $\mathrm{T}$-common region, such as PAb419, or the C-terminus of the $\mathrm{T}$ antigen, co-immunoprecipitate $\mathrm{Cul}-7$ and the $\mathrm{T}$ antigen, whereas PAb416 does not [19]. Similarly, Cotsiki et al. [9], in investigating the binding of Bub-1 to the T antigen, indicated that binding could only be demonstrated when the $\mathrm{T}$ antigen was immunoprecipitated with an antibody that binds to the extreme C-terminus. They suggested that the PAb416 epitope was not accessible when Bub-1 was bound. They showed further that deletion of amino acids 89-97 completely eliminated Bub-1 binding, and mutations of any one of the three tryptophan residues within T-antigen amino acids 91-95 (dl91-95) were sufficient to reduce Bub-1 binding. Conversely, the dl89$97 \mathrm{~T}$-antigen mutant retained the ability to bind $\mathrm{Rb}$ and Hsc70 and retained J-domain function $[9,10]$.

Kohrman and Imperale [19] (1992) provided evidence that Cul-7 also co-immunoprecipitated with T1-121. Ali et al. [8] (2004) showed further that deletion of amino acids 98-102 from the full-length $\mathrm{T}$ antigen dramatically reduced Cul-7 binding, and changing amino acid 98 to alanine (F98A) diminished binding, whereas individually changing amino acids 99, 100, and 102 did not. PAb416 could not immunoprecipitate Cul-7:T-antigen complexes, and this antibody displaced Cul-7 from existing complexes [19]. Kasper et al. [10] (2005) showed that amino acids in the T-common region also contribute to Cul-7 binding. The deletion of amino acids 69-83 completely abolished binding, and specific single amino acid substitutions (F74R, F74A), and the deletion of amino acids 71-74 within that region partially reduced Cul-7 binding. The results indicated that amino acids within the 69-83 region were involved in Cul-7 binding directly or in conferring the necessary configuration of the T-antigen $\mathrm{N}$ - 


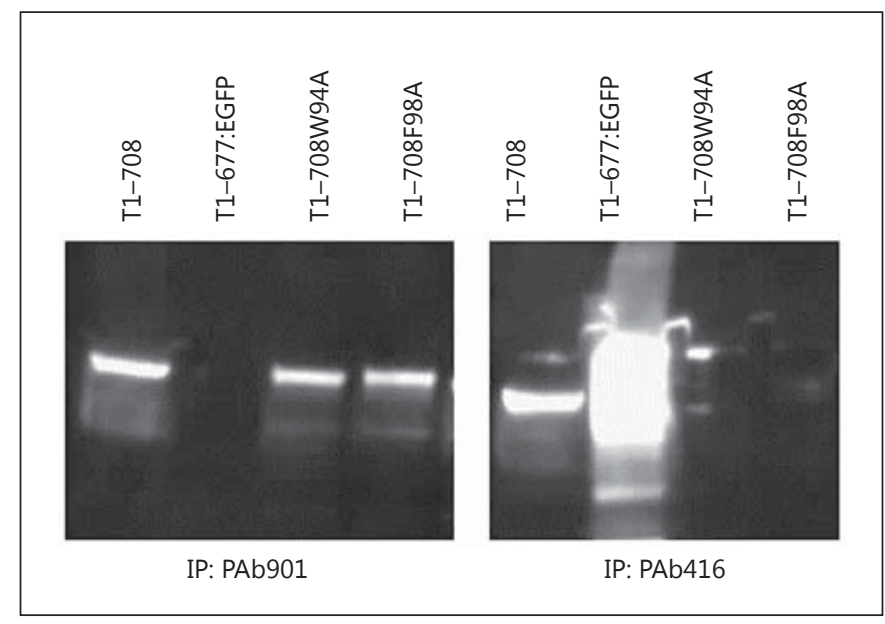

Fig. 2. Immunoprecipitation-Western blot of the full-length $\mathrm{T}$ antigen (T1-708), T1-677:EGFP, or T antigens containing the amino acid substitution W94A or F98A from transiently transfected CV1 cells immunoprecipitated by PAb901 (left panel) or PAb416 (right panel) and probed with PAb901. IP = Immunoprecipitation.

terminus. The authors were led to investigate the role of the T-common region by the observation, based on the crystal structure of the N-terminus of T antigen bound to $\mathrm{Rb}$, that the region containing amino acid 98 was not available for Cul-7 binding. They suggested that changing amino acid 98 to alanine altered the configuration of the T-common region and prevented Cul-7 binding [10].

The observations that multiple cellular proteins bind to the T-common region (Hsc70) or within the neighboring region of amino acids 83-107 (Bub-1, Cul-7, and $\mathrm{Rb}$ family members), and the ability of PAb416 to displace or prevent the binding of Bub-1 and Cul-7 to the T antigen suggested that monoclonal antibodies with epitopes within these regions might prove useful to probing the relationships among mutations that prevent the binding of specific cellular proteins and potential consequent conformational changes. Accordingly, we investigated the effects of mutations that prevent Bub-1, Cul-7, Rb, and Hsc70 binding to the $\mathrm{T}$ antigen on recognition of the $\mathrm{T}$ antigen by specific monoclonal antibodies in the context of full-length and $\mathrm{N}$-terminal $\mathrm{T}$-antigen fragments.

We examined the effect of the mutations T1-708W94A and $\mathrm{T} 1-708 \mathrm{~F} 98 \mathrm{~A}$, which prevent the $\mathrm{T}$ antigen from binding Bub-1 or Cul-7, respectively, on the ability of PAb416 to detect the T antigen. Specifically, plasmids expressing the wild-type T antigen (T1-708) or the mutant $\mathrm{T}$ antigens were transfected into CV1 cells. Protein extracts were prepared $48 \mathrm{~h}$ later, immunoprecipitated with either PAB901 or 416, and followed by PAGE (4-16\% gel). The $\mathrm{T}$ antigen was detected by Western blot using PAb901, which recognizes an epitope (amino acids 684698 ) in the C-terminus of the T antigen $[20,21]$. A T1677:EGFP C-terminal fusion construct lacking the PAb901epitope was included as an antibody specificity control for PAb901. The results are shown in figure 2. PAb901 immunoprecipitated and detected all $\mathrm{T}$ antigens containing the epitope, whereas PAb416 did not immunoprecipitate T1-708W94A or T1-708F98A. The finding that the W94A mutation prevented the binding and precipitation of the mutant T antigen by PAb416 was expected, since W94 is within the minimal epitope for PAb416 as determined by peptide binding [18].

The failure of PAb416 to detect T1-708F98A was unexpected since amino acid 98 lies outside of the minimal epitope. However, the relevance of F98 for PAb416 binding in the context of the full-length protein is consistent with the ability of the antibody to displace Cul-7 from complexes with the $\mathrm{T}$ antigen $[10,19]$. In re-examining binding between the $\mathrm{T}$ antigen and Cul-7, Kasper et al. [10] (2005) suggested that the failure of T1-708F98A to bind Cul-7 may result from the distortion of the portion of the T-common region containing amino acids 69-83, a region that is also essential. To address that possibility we compared the ability of an antibody with a conformation-dependent epitope (PAb902) and one with a conformation-independent epitope (PAb419), both within the $\mathrm{T}$-common region, to immunoprecipitate $\mathrm{N}$-terminal $\mathrm{T}$ antigen fragments. N-terminal fragments were used in this experiment because these contain the minimal region that encompasses all amino acids required for Bub-1, Cul-7, and PAb416 binding and to rule out the involvement of more C-terminal activities or structural elements in altering or maintaining the conformation of the $\mathrm{T}$ common region. A possible association between the common region and the C-terminal portion of the $\mathrm{T}$ antigen was suggested by the observation that PAb419 alters the ability of $\mathrm{T}$ to complex with $\mathrm{p} 53$, using purified proteins [22], under specific conditions.

Figure 3 shows the results of immunoprecipitating the wild-type $\mathrm{T}$ antigen, the $17 \mathrm{KT}$ antigen, or T-antigen $\mathrm{N}$ terminal fragments T1-121t-, with or without the W94A (T1-121t-W94A) or F98A (T1-121t-F98A) substitutions from cell lines using PAb902 or PAb416. Proteins were detected by Western blot using PAb419 as the probe. In this experiment $\mathrm{N}$-terminal proteins were expressed from plasmids that do not produce the small $t$ antigen, which would migrate similarly to T1-121 and $17 \mathrm{KT}$ in the gel system used. The W94A mutation was used primarily as 
a control for the specificity of PAb416. Full-length T (T1708), T1-121t-, and 17KT were immunoprecipitated by both antibodies. T1-121t-W94A and T1-121t-F98A were immunoprecipitated by PAb902 but not PAb416. These results indicated that the F98A mutation did not globally distort the T-common region, since the conformation-dependent PAb902 epitope was maintained. Similarly, the W94A alteration in the context of the Nterminal fragment remained essential to the PAb416 epitope and did not distort the linear epitope or conformation of the epitopes marked by the PAb902 antibody.

It has previously been shown that PAb416 immunoprecipitates the majority of the $\mathrm{T}$ antigen from protein extracts [23]. The results in figure 3 show that PAb416 and PAb902 immunoprecipitated similar amounts of T antigen from cells expressing T1-121t- and $17 \mathrm{KT}$. It is likely, therefore, that PAb902 immunoprecipitated the bulk of the $\mathrm{T}$ antigen and not a conformational subclass of $\mathrm{T}$ that remains unaffected by the amino acid 94 or 98 substitutions. The conformation-dependent epitope for PAb902 within the T-common region has not been defined. The major functional determinant within the Tcommon region is the hexapeptide (HPDKGG), which is essential for binding Hsc70. The suggestion that the F98A substitution might alter the conformation within the Tcommon region led us to investigate the effect of mutations within the hexapeptide ( $\mathrm{T}$-antigen amino acids 42 47) on PAb416 or PAb902 binding. Accordingly, T antigens were detected by direct Western blotting (fig. 4a) or immunoprecipitation (fig. 4b) from protein extracts of cell lines expressing wild-type T (T1-708), or T antigens with the amino acid substitutions H42Q [24], D44N [25], P43L/K45N, or D44E/G47R [26] by PAb902, PAb416, or PAb901. Immunoprecipitated proteins were detected by probing with the C-terminal-specific PAb901. As controls, extracts of cell lines expressing T1-708K1 (E107K) [27], which cannot bind the Rb family proteins and $\mathrm{T} 83-$ 708 [21], which does not contain the T-common region, were treated similarly. This experiment was conducted using the full-length T antigen, since Sullivan et al. [28] (2001) showed that an N-terminal fragment (T1-136) was not sufficient for stable Hsc70 binding. As expected, all of the proteins were recognized in the direct Western blot and were immunoprecipitated by PAb901. PAb416 also recognized all of the denatured proteins on the direct Western blot and precipitated all of the native T antigens. PAb902 immunoprecipitated all of the $\mathrm{T}$ antigens except T83-708, which does not contain the T-common region. These results show that mutations disabling the Hsc70 binding function do not affect PAb416 binding. In addi-

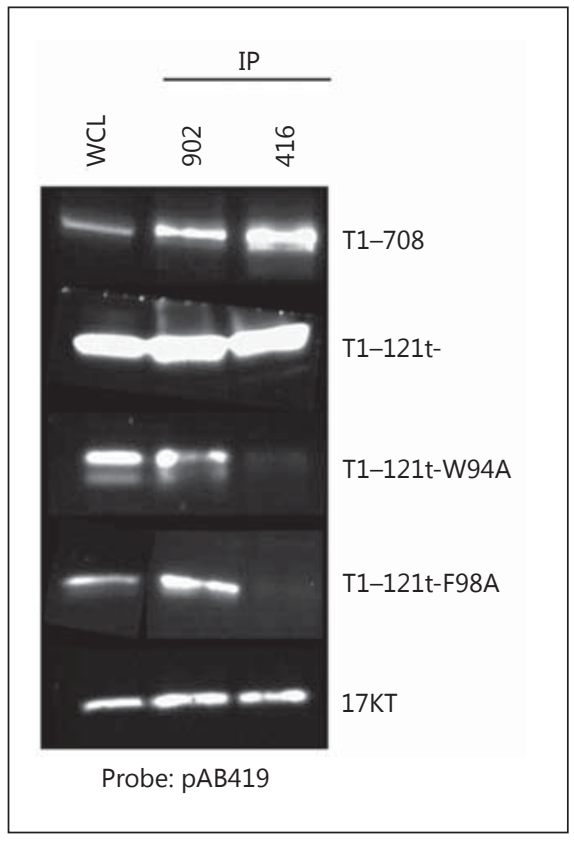

Fig. 3. Immunoprecipitation of wild-type, T1-121t- or mutant Nterminal T-antigen fragments from cell lines with PAb902 or PAb416. IP = Immunoprecipitation; $\mathrm{WCL}=$ whole cell lysates. Whole cell lysates $(750 \mu \mathrm{g})$ were immunoprecipitated and subjected to Western analysis with PAb419 as probe. Untreated whole cell lysate $(75 \mu \mathrm{g})$ was used as a control. Extracts were prepared from rat cells transformed with the $\mathrm{T}$-antigen fragments plus mutant ras.

tion, they show that amino acids $42,44,45$, and 47 are not required for, and do not globally distort, the common region necessary for the binding of the conformation-dependent PAb902 antibody.

Each of the four cellular proteins, Hsc70, Bub-1, Cul-7, and $\mathrm{Rb}$, that bind within the first $107 \mathrm{~T}$-antigen amino acids utilizes an independent binding site, as mutational inactivation of any one site does not prevent binding or the functional consequences of binding the other proteins $[9,10]$. Mutational analysis implicated two regions of the T antigen in binding Cul-7 $[8,10]$. Introducing the F98A change diminished binding, and deletion of amino acids 69-83 prevented Cul-7 binding. The authors suggested that changing amino acid 98 to alanine altered the configuration of the T-common region to prevent Cul-7 binding.

It is shown here that $\mathrm{T}$ antigens with the $\mathrm{F} 98 \mathrm{~A}$ change, whether in the context of the full-length protein or short $\mathrm{N}$-terminal fragments (T1-121) were immunoprecipitated by PAb902. Therefore, it seems unlikely that the Tcommon region, which contains the conformation-dependent PAb902 epitope, was globally altered, although 


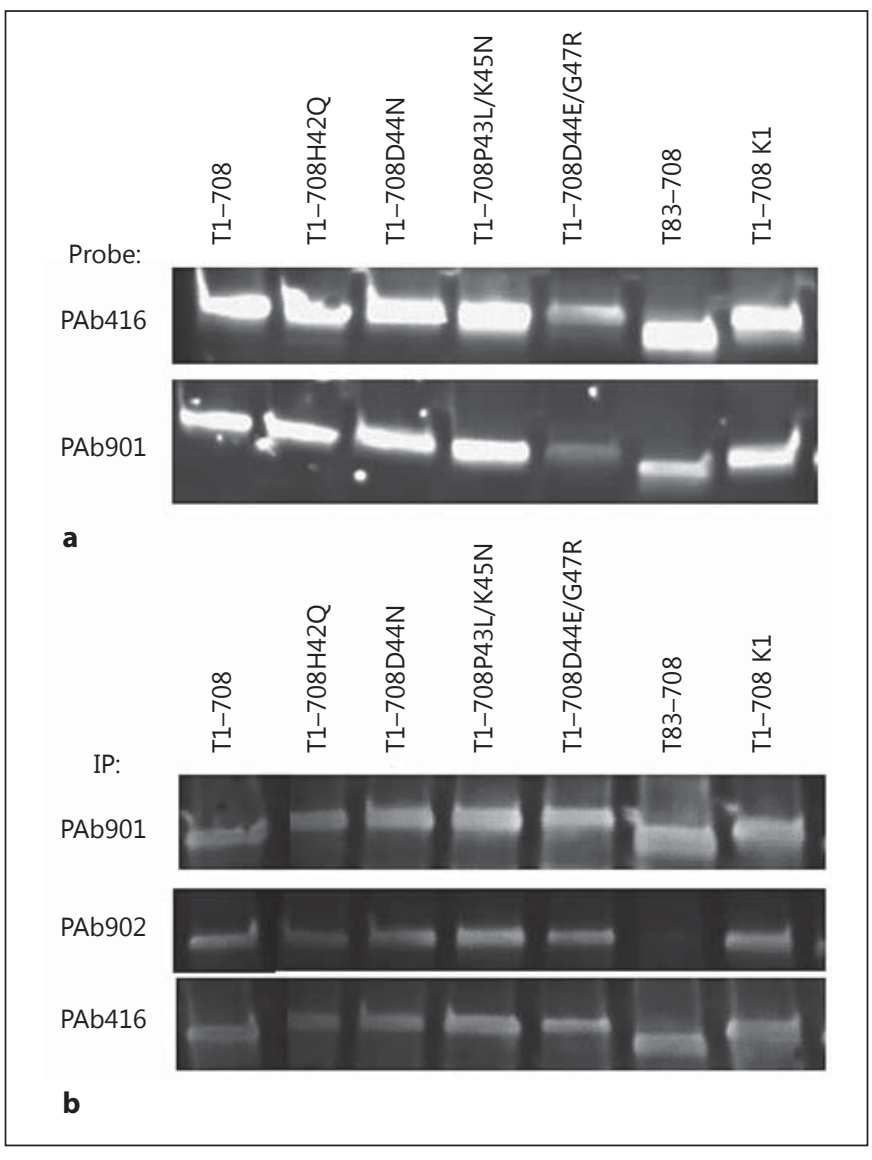

Fig. 4. Effect of J-domain mutations on the recognition of T antigen by PAb416. IP = Immunoprecipitation. Whole cell extracts from rat cell lines expressing mutant ras and T-antigen mutants were loaded onto duplicate gels and subjected to direct Western blot $(100 \mu \mathrm{g}$; a) or immunoprecipitation $(750 \mu \mathrm{g})$ followed by Western analysis (b). The C-terminal PAb901 antibody was used as a probe for the immunoprecipitated proteins. Wild-type $\mathrm{T}$ and T1-708E107K (K1 mutation) were included as controls.

localized distortion might occur. Similarly, T1-708 containing the F98A substitution retains the ability to bind Hsc70 [8], indicating that the hexapeptide binding site, $\mathrm{T}$-antigen amino acids $42-47$, remains accessible. Additionally, we show that P43L/K45N or D44E/G47R alterations of the hexapeptide do not globally distort the common region. Although PAb419 inhibits the association between the T antigen and Hsc70 and is likely to displace Hsc70 once bound to the $\mathrm{T}$ antigen, mutations within the Hsc70 binding site do not prevent PAb419 from immunoprecipitating the $\mathrm{T}$ antigen [28]. These findings suggest that T-antigen amino acids $42-45$ and 47 either are not within the PAb419 linear epitope or that their alteration in the combinations tested are not sufficient to prevent antibody binding. Similarly, amino acids $69-83$ are unlikely to be critical for binding PAb419, since a mutant T antigen missing amino acids 69-83 can be immunoprecipitated or detected by that antibody [8]. Additionally, PAb419 does not recognize the JC virus T antigen [29]; however, PAb416 does [30]. The three essential T-antigen tryptophan residues (amino acids 91, 94, and 95) in the minimal PAb416 epitope as defined by peptide binding are conserved among the SV40, JCV, BKV, and LPV T antigens. The phenylalanine 98 is also conserved in all of these proteins. The observation that the F98A substitution prevents $\mathrm{PAb} 416$ binding and that $\mathrm{F} 98$ is conserved among these $T$ antigens, in conjunction with the new information reported here, indicates that in the context of the native protein, F98 contributes to the PAb416 epitope.

The finding that PAb416 displaced Bub-1 and Cul-7 from the $\mathrm{T}$ antigen is consistent with the proximity of the mutations that disrupt their binding (dl89-97 and 91-95, respectively). The binding sites for Bub-1 and the PAb416 overlap. Altering the same tryptophans prevents binding of both Bub-1 and the antibody. The Cul-7 and PAb416 binding sites, however, do not appear to be identical. Amino acid 98 when changed to alanine prevents both Cul-7 and PAb416 binding, and Cul-7 binding requires amino acids within the $\mathrm{T}$-common region (amino acids 69-83). To reconcile the apparent requirement for F98 in Cul-7 binding with evidence indicating that F98 is not accessible, at least in the context of the $\mathrm{T}$ antigen bound to full-length Rb [10], Kasper et al. [10] (2005) suggest that altering F98 prevents the maintenance of a conformation within the common region needed for Cul-7 binding. We show here by using a conformation-dependent antibody whose epitope is within the first $82 \mathrm{~T}$-antigen amino acids that the T-common region is not globally disordered by the F98A change or by specific mutations within the J domain, Bub-1, or Cul-7 binding sites. Others have shown that changing amino acid 98 does not alter known functions within the J domain.

Finally, PAb416 [23] and PAb902 immunoprecipitate the bulk of the $\mathrm{T}$ antigen from cell extracts and, therefore, recognize a predominant $\mathrm{T}$-antigen conformation. $\mathrm{T}: \mathrm{Rb}$ complexes, while functionally critical to disrupting cell growth control, represent a minor subpopulation. Dyson et al. [30] (2005) showed that PAb416 co-immunoprecipitated $\mathrm{Rb}$ peptides with either the JCV or SV40 T antigen. It appears, then, that F98 is accessible to interact with PAb416 when C-terminal Rb peptides are bound. The possibility remains that the subpopulation of the $\mathrm{T}$ antigen bound to full-length $\mathrm{Rb}$ results in a conformation that may render amino acid 98 inaccessible. 


\section{References}

1 Cheng J, et al: Cellular transformation by Simian Virus 40 and Murine Polyoma Virus $\mathrm{T}$ antigens. Semin Cancer Biol 2009;19:218228.

2 Simmons DT, et al: Simian virus 40 large T antigen binds to topoisomerase I. Virology 1996;222:365-374.

3 Auborn KJ, et al: Identification of DNA-protein interactions and enhancer activity at the $5^{\prime}$ end of the upstream regulatory region in human papillomavirus type 11 . Virology 1989;170:123-130.

4 Scheller A, et al: A small subclass of SV40 T antigen binds to the viral origin of replication. Cell 1982;29:375-383.

5 Stahl $\mathrm{H}$, et al: A large-tumor antigen-specific monoclonal antibody inhibits DNA replication of simian virus 40 minichromosomes in an in vitro elongation system. J Virol 1985;54: 473-482.

6 Ahuja D, Saenz-Robles MT, Pipas JM: SV40 large $\mathrm{T}$ antigen targets multiple cellular pathways to elicit cellular transformation. Oncogene 2005;24:7729-7745.

7 Saenz Robles MT, Pipas JM: T antigen transgenic mouse models. Semin Cancer Biol 2009, 19:229-235.

8 Ali SH, et al: Cul7/p185/p193 binding to simian virus 40 large $\mathrm{T}$ antigen has a role in cellular transformation. J Virol 2004;78:2749_ 2757.

9 Cotsiki M, et al: Simian virus 40 large T antigen targets the spindle assembly checkpoint protein Bub1. Proc Natl Acad Sci USA 2004 101:947-952.

10 Kasper JS, et al: Simian virus 40 large $\mathrm{T}$ antigen's association with the CUL7 SCF complex contributes to cellular transformation. J Virol 2005;79:11685-11692.

11 Hein J, et al: Simian virus 40 large $T$ antigen disrupts genome integrity and activates a DNA damage response via Bub1 binding. J Virol 2009;83:117-127.
12 DeCaprio JA, et al: SV40 large tumor antigen forms a specific complex with the product of the retinoblastoma susceptibility gene. Cell 1988;54:275-283.

13 Ewen ME, et al: An N-terminal transformation-governing sequence of SV40 large T antigen contributes to the binding of both p110Rb and a second cellular protein, p120. Cell 1989;58:257-267.

14 Tevethia MJ: Immortalization of primary mouse embryo fibroblasts with SV40 virions, viral DNA, and a subgenomic DNA fragment in a quantitative assay. Virology 1984;137: 414-421.

15 Harlow E, et al: Monoclonal antibodies specific for simian virus 40 tumor antigens. J Virol 1981;39:861-869.

16 Zerrahn J, et al: Independent expression of the transforming amino-terminal domain of SV40 large I antigen from an alternatively spliced third SV40 early mRNA. EMBO J 1993;12:4739-4746.

17 Cavender JF, et al: Simian virus 40 large $\mathrm{T}$ antigen contains two independent activities that cooperate with a ras oncogene to transform rat embryo fibroblasts. J Virol 1995;69:923934.

18 Lindner K, Mole SE, Lane DP, Kenny MK: Epitope mapping of antibodies recognising the N-terminal domain of simian virus large tumour antigen. Intervirology 1998;41:1016.

19 Kohrman DC, Imperiale MJ: Simian virus 40 large $\mathrm{T}$ antigen stably complexes with a 185-kilodalton host protein. J Virol 1992;66: 1752-1760.

20 Tevethia MJ, et al: A simian virus 40 large Tantigen segment containing amino acids $1-127$ and expressed under the control of the rat elastase-1 promoter produces pancreatic acinar carcinomas in transgenic mice. J Virol 1997;71:8157-8166.

21 Cavender JF, Mummert C, Tevethia MJ: Transactivation of a ribosomal gene by simian virus 40 large- $T$ antigen requires at least three activities of the protein. J Virol 1999;73:214224.
22 Kernohan NM, Hupp TR, Lane DP: Modification of an $\mathrm{N}$-terminal regulatory domain of $\mathrm{T}$ antigen restores $\mathrm{p} 53-\mathrm{T}$ antigen complex formation in the absence of an essential metal ion cofactor. J Biol Chem 1996;271:49544960.

23 Auborn K, Guo M, Prives C: Helicase, DNAbinding, and immunological properties of replication-defective simian virus 40 mutant T antigens. J Virol 1989;63:912-918.

24 Stubdal $\mathrm{H}$, et al: Inactivation of $\mathrm{pRB}$-related proteins p130 and p107 mediated by the J domain of simian virus 40 large $\mathrm{T}$ antigen. Mol Cell Biol 1997;17:4979-4990.

25 Peden KW, Pipas JM: Simian virus $40 \mathrm{mu}$ tants with amino-acid substitutions near the amino terminus of large $\mathrm{T}$ antigen. Virus Genes 1992;6:107-118.

26 Porras A, et al: A novel simian virus 40 earlyregion domain mediates transactivation of the cyclin A promoter by small-t antigen and is required for transformation in small-t antigen-dependent assays. J Virol 1996;70:69026908.

27 Kalderon D, et al: A short amino acid sequence able to specify nuclear location. Cell 1984;39:499-509.

28 Sullivan CS, Gilbert SP, Pipas JM: ATP-dependent simian virus $40 \mathrm{~T}$-antigen-Hsc70 complex formation. J Virol 2001;75:16011610.

29 Deckhut AM, et al: Localization of common cytotoxic T lymphocyte recognition epitopes on simian papovavirus SV40 and human papovavirus JC virus T antigens. Virology 1991; 183:122-132.

30 Dyson N, et al: Large T antigens of many polyomaviruses are able to form complexes with the retinoblastoma protein. J Virol 1990;64: 1353-1356.
Cul-7 and Bub-1 Binding Mutants Maintain Conformation of Epitope
Intervirology 2016;59:30-35 DOI: $10.1159 / 000446777$ 